\title{
Comparison of medical therapy with renal denervation in patients with resistant hypertension
}

\author{
Palaparti R. ${ }^{1 *}$, Syed I. ${ }^{2}$
}

DOI: https://doi.org/10.17511/ijmrr.2019.i06.17

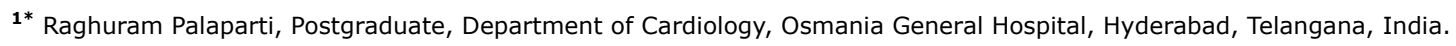

2 Imamuddin Syed, Professor, Department of Cardiology, Osmania General Hospital, Hyderabad, Telangana, India.
}

Introduction: Catheter-based renal denervation selectively reduces renal sympathetic efferent activity and is accompanied by an increase in renal blood flow and reduction in plasma renin activity. Thus, ablation of afferent and efferent renal nerves in patients with treatment-resistant hypertension probably leads to reductions in blood pressure. Material and methods: The present study conducted a non-randomized case-control study and enrolled 15 patients who underwent renal denervation therapy for resistant hypertension as cases and 16 patients who were on medical management for resistant hypertension served as controls. Results: It was found that catheter based renal denervation is safe, significantly reduces blood pressure at 1 month, 3 months and 6 months of follow-up without any major adverse events. It was observed that a significant BP reduction when compared to patients only on medical therapy. The mean number of drugs decreased significantly in the denervation group in follow-up. Conclusions: Though the present study showed a significant BP reduction in patients with renal denervation, a significant effect on BP was not observed in a large randomized trial simplicity HTN-3 and major criticism was on the trials design and neuroscience failings. Even today the clinical dilemma is still continuing and further evaluation in rigorously designed clinical trials are necessary to validate alternative methods of renal denervation or to confirm previously reported benefits of renal denervation. The current study anticipate that future trials will also address the effectiveness of renal denervation in disease states other than hypertension.

Keywords: Comparison, Medical therapy, Renal denervation, Resistant hypertension

Corresponding Author

Raghuram Palaparti, Postgraduate, Department of Cardiology, Osmania General Hospital, Hyderabad, Telangana, India.

Email: drraghuram10@gmail.com
How to Cite this Article

To Browse

Palaparti R, Syed I. Comparison of medical therapy with renal denervation in patients with resistant hypertension. Int J Med Res Rev. 2019;7(6):559567.

Available From

https://ijmrr.medresearch.in/index.php/ijmrr/article/ view/1116

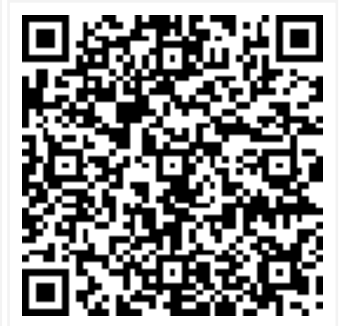

Manuscript Received 2019-11-10

Conflict of Interest No
Review Round 1 2019-11-20

Funding $\mathrm{Nil}$
Review Round 2 2019-11-28

Ethical Approval Yes
Review Round 3

Plagiarism X-checker $4 \%$
Accepted 2019-12-03

Note

(c) 2019 by Raghuram Palaparti, Imamuddin Syed and Published by Siddharth Health Research and Social Welfare Society. This is an Open Access article licensed under a Creative Commons Attribution 4.0 International License https://creativecommons.org/licenses/by/4.0/ unported [CC BY 4.0]. 


\section{Introduction}

Resistant hypertension is defined as uncontrolled blood pressure despite the use of optimal doses of three antihypertensive agents, of which one is a diuretic. Using this definition prevalence of resistant hypertension can be as high as $30 \%$ in some recent studies $[1,2]$. The kidney is richly innervated with baroreceptors and chemoreceptors.

Renal denervation reduces whole-body noradrenaline spillover and reduces sympathetic nerve traffic to the skeletal muscle vasculature, as measured by muscle sympathetic nerve activity after renal sympathetic denervation. Catheter-based renal denervation selectively reduces renal sympathetic efferent activity and is accompanied by an increase in renal blood flow and reduction in plasma renin activity.

Thus, ablation of afferent and efferent renal nerves in patients with treatment-resistant hypertension probably leads to reductions in blood pressure [3]. Hence, the study was planned to assess the safety and effectiveness of renal denervation in patients with resistant hypertension.

\section{Patients and Methods}

Setting: The study was conducted in a tertiary care government general hospital (Osmania General Hospital, Hyderabad) after institutional ethics comittee approval.

Study duration: The study was conducted over a duration of 2 years. Patients were recruited from cardiology outpatient department and informed consent has been obtained from all the patients.

Study type: The study was a non randomized case control study where 15 patients were enrolled who underwent renal denervation therapy for resistant hypertension as cases and 16 patients who were on medical management for resistant hypertension served as controls.

Inclusion criteria- Patients aged $18-85$ years with a systolic blood pressure of $160 \mathrm{~mm} \mathrm{Hg}$ or more ( $\geq 150 \mathrm{~mm} \mathrm{Hg}$ in patients with type 2 diabetes), despite compliance with three or more antihypertensive drugs were included.

Exclusion criteria- Patients with valvular heart disease, pregnancy or planned pregnancy during the study, a history of myocardial infarction, unstable angina, or cerebro-vascular accident in the previous
6 months, patients with hemodynamically significant renal artery stenosis, previous renal artery intervention, or renal artery anatomy that precluded treatment (defined as $<4 \mathrm{~mm}$ diameter, $<20 \mathrm{~mm}$ length, or more than one main renal arteries) in RDN group and patients who did not give written valid consent were excluded from the study.

Primary endpoints:1) Change in average officebased measurements of systolic blood pressure (SBP), diastolic blood pressure (DBP) and mean blood pressure (MBP) from baseline to 6 months in both cases and controls. 2) Comparison of Blood pressure reduction between cases (after RDN) and controls (with drug therapy) at 6 months

Secondary endpoints:1) Acute procedural safety in RDN group and adverse drug reactions in controls. 2) Chronic procedural safety (reduction of eGFR $>25 \%$ or new stenosis $>60 \%$ / renal artery aneurysm at 6 months) in cases and cardiovascular mortality at 6 months in both groups

Data collection procedure: Eligible patients were treated either with the renal denervation or medical therapy with subsequent follow-up to 6 months. Assessment included physical examination, recording baseline blood-pressure and renal function measurements. Renal artery anatomical screening with renal duplex, computed tomography, MRI, or renal angiography to confirm anatomical eligibility. Baseline serum creatinine, spot urine albumin-tocreatinine ratio, electrolytes, eGFR, 24-h ABPM before inclusion in RDN group at baseline were recorded.

Patients (cases and controls) were followed up at 1 , 3 and 6 months. At follow up renal artery Doppler or renal CT angiography or renal MRA was done to assess the renal artery for stenosis, pseudoaneurysm or dissection in RDN group. A $7 f$ femoral sheath was introduced into the right common femoral artery and diagnostic renal angiography was done using Judkins right catheter.

After the knowledge of renal vascular anatomy, the treatment catheter (conventional radio-frequency ablation catheter) was introduced into each renal artery via femoral access. Conventional catheter was used, unlike simplicity catheter used in simplicity trials because of cost constraints. Procedure was done in local anesthesia and under conscious sedation using midazolam and fentanyl. Post procedure sedation and analgesia were used if required. 
Discrete, radiofrequency ablations were applied lasting up to 2 min each and of 8 watts or less to obtain up to six ablations separated both longitudinally and rotationally within each renal artery. Simultaneous bilateral renal artery denervation was performed in all patients. Triplicate office blood pressures were measured with standard joint national committee VIII guidelines [4].

Averages of the triplicate measures was used. Patients were instructed to remain adherent to their prescribed anti hypertensive drugs. Information regarding medications and doses at all follow-up time points was collected. The enrollment criteria, evaluation of patients and study procedure were same in control group except for that the controls are continued on optimal medical therapy instead of denervation therapy. Patient's blood pressures were recorded at every OPD visit and any change in medications (either decrease or increase in doses or drugs) noted. Strict compliance to medications was ensured with counseling and frequent phone calls if required.

Data analysis: Outcomes were assessed for safety, effectiveness of renal sympathetic nerve denervation, and change in office blood pressure in both cases and controls. Mean changes were calculated in the office blood pressures from baseline. Analysis was done with SPSS version 21.0.

\section{Results}

The mean age of the renal denervation group and drug therapy group are $49.4 \pm 13.3$ years and $55.6 \pm 7.7$ years respectively. $66.7 \%(n=10)$ of the renal denervation group and $56.3 \%(n=9)$ of the drug therapy group are constituted by males. There is no statistically significant difference in age and sex distribution among both the groups ( $p=0.552)$. Only one female patient in the RDN group and 2 patients in drug therapy group are known cases of hypothyroidism and on hormone supplementation. There is no statistically significant difference in the prevalence of smoking habit, diabetes, drug therapy, coronary artery disease, renal disease among the two groups ( $p=0.433)$. The mean SBP, $\mathrm{DBP}$ and MBP at baseline in the renal denervation group are $190.7 \pm 25.8,100.7 \pm 11.6 \mathrm{~mm}$ of $\mathrm{Hg}$ and $130.7 \pm 15.5 \mathrm{~mm}$ of $\mathrm{Hg}$ respectively. The mean SBP, DBP and MBP at baseline in the drug therapy group are $183.1 \pm 14.5 \mathrm{~mm}$ of $\mathrm{Hg}, 105.6 \pm 6.3 \mathrm{~mm}$ of $\mathrm{Hg}$ and $131.5 \pm 8.0 \mathrm{~mm}$ of $\mathrm{Hg}$ respectively. The differences at baseline are not statistically significant.
The mean SBP, DBP and MBP at 1 month after procedure in the renal denervation group are $136.6 \pm 11.8 \mathrm{~mm}$ of $\mathrm{Hg}, 80.7 \pm 5.9 \mathrm{~mm}$ of $\mathrm{Hg}$ and $99.3 \pm 7.4 \mathrm{~mm}$ of $\mathrm{Hg}$ respectively. The mean SBP, DBP and MBP at 1 month in the drug therapy group are $163.8 \pm 9.6 \mathrm{~mm}$ of $\mathrm{Hg}, 99.4 \pm 2.5 \mathrm{~mm}$ of $\mathrm{Hg}$ and $120.8 \pm 4.5 \mathrm{~mm}$ of $\mathrm{Hg}$ respectively. The mean differences of SBP, DBP, MBP at 1 month after procedure of the renal denervation group from drug therapy group are $-27.1 \pm 3.84 \mathrm{~mm}$ of $\mathrm{Hg},-18.7 \pm 1.6$ $\mathrm{mm}$ of $\mathrm{Hg},-21.5 \pm 2.17 \mathrm{~mm}$ of $\mathrm{Hg}$ respectively. The difference is statistically significant ( $p<0.005)$.

The mean SBP, DBP and MBP at 3 months after procedure in the renal denervation group are $134.7 \pm 13.6 \mathrm{~mm}$ of $\mathrm{Hg}, 81.3 \pm 5.2 \mathrm{~mm}$ of $\mathrm{Hg}$ and $99.1 \pm 7.4 \mathrm{~mm}$ of $\mathrm{Hg}$ respectively. The mean SBP, DBP and MBP at 3 months in the drug therapy group is $156.9 \pm 13.0 \mathrm{~mm}$ of $\mathrm{Hg}, 95.6 \pm 6.3 \mathrm{~mm}$ of $\mathrm{Hg}$ and $116.0 \pm 7.7 \mathrm{~mm}$ of $\mathrm{Hg}$ respectively. All the values are lower in renal denervation group and the mean differences of SBP, DBP, MBP in renal denervation group from drug therapy group at 3 months are $-22.2 \pm 4.78 \mathrm{~mm}$ of $\mathrm{Hg},-14.3 \pm 2.1 \mathrm{~mm}$ of $\mathrm{Hg}$ and $-16.9 \pm 2.7 \mathrm{~mm}$ of $\mathrm{Hg}$ respectively. This difference is statistically significant $(p<0.005)$

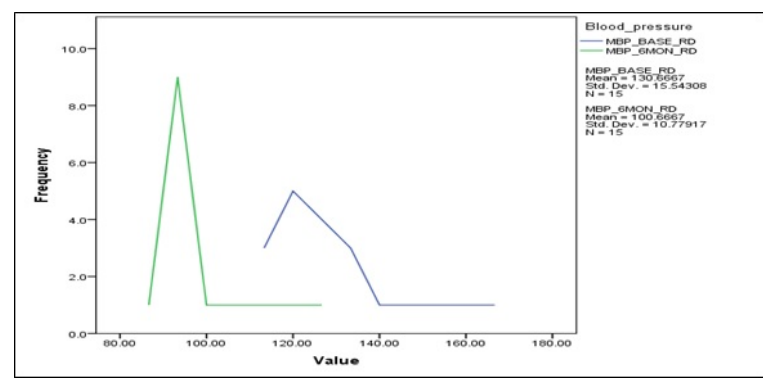

Fig-1: The mean blood pressure (MBP) reduction in the renal denervation group at 6 months.

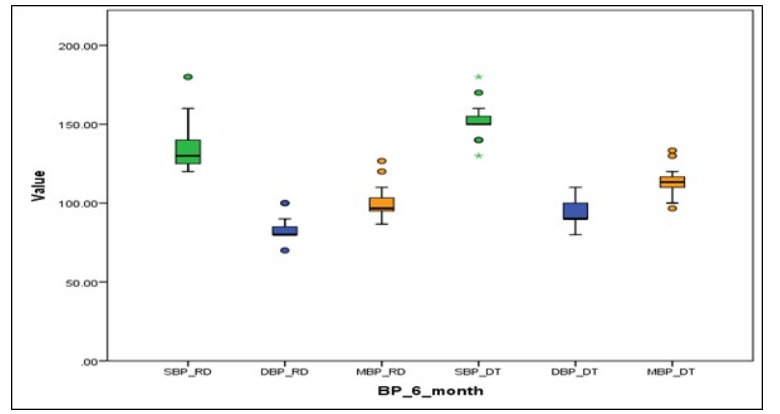

Fig-2: The SBP, DBP and MBP reductions in both renal denervation group and drug therapy group at 6 months. 
The mean SBP, DBP and MBP at 6 months after procedure in the renal denervation group are $135.3 \pm 16.9 \mathrm{~mm}$ of $\mathrm{Hg}, 83.3 \pm 8.2 \mathrm{~mm}$ of $\mathrm{Hg}$ and $100.7 \pm 10.8 \mathrm{~mm}$ of $\mathrm{Hg}$ respectively. The mean SBP, DBP and MBP at 6 months in the drug therapy group are $152.0 \pm 12.1 \mathrm{~mm}$ of $\mathrm{Hg}, 94.7 \pm 9.2 \mathrm{~mm}$ of $\mathrm{Hg}$ and $113.8 \pm 9.7 \mathrm{~mm}$ of $\mathrm{Hg}$ respectively.

All the values are lower in renal denervation group (Figure 1) and the mean differences of SBP, DBP and MBP at 6 months are $-16.7 \pm 5.4 \mathrm{~mm}$ of $\mathrm{Hg}$, $-11.3 \pm 3.2 \mathrm{~mm}$ of $\mathrm{Hg}$ and $-13.1 \pm 3.7 \mathrm{~mm}$ of $\mathrm{Hg}$ respectively. This difference is statistically significant $(p=0.002)$ (Figure 2). Table 1 shows the mean fall in absolute BP recordings in renal denervation group when compared to drug therapy group.

Table-1: Mean fall in absolute BP recordings.

\begin{tabular}{|l|l|l|l|l|l|l|}
\hline & RDN & RDN & RDN & DRUG Rx & DRUG Rx & DRUG Rx \\
\cline { 2 - 7 } & SBP & DBP & MBP & SBP & DBP & MBP \\
\hline 1 mon $\triangle B P$ & 54 & 20 & 31.3 & 19.4 & 6.3 & 10.6 \\
\hline 3 mon $\triangle B P$ & 56 & 19.3 & 31.6 & 26.2 & 10 & 15.4 \\
\hline 6 mon $\triangle B P$ & 55.3 & 17.3 & 30 & 32 & 11.3 & 18.2 \\
\hline
\end{tabular}

The mean number of drugs at 6 months post procedure in the renal denervation group is 2.5 compared to $4.0 \pm 0.5$ in the drug therapy group ( $p$ $=0.001)$. There was no statistically significant change in eGFR pre and post intervention in both the groups.

There were two adverse effects reported in the study population, one patient required a transfusion for groin hematoma and another patient developed a femoral pseudo-aneurysm at the puncture site which was managed surgically. One patient died during the study period in the drug therapy group at 5 months and was excluded from analysis of sixmonth blood pressures. The cause of death is hemorrhagic CVA.

\section{Discussion}

Hypertension is the most common condition seen in primary care and leads to myocardial infarction, stroke, renal failure, and death if not detected early and treated appropriately. Identifiable causes of hypertension like chronic Kidney Disease, coarctation of aorta, cushings syndrome, drug induced causes, obstructive uropathy, pheochromocytoma, primary aldosteronism and other mineralocorticoid states, renovascular hypertension, sleep apnea, thyroid and parathyroid abnormalities should be screened and treated before labeling it as essential hypertension.
Appropriate investigations should be conducted when there is a high index of suspicion of an identifiable cause [5]. More than two-thirds of hypertensive individuals cannot be controlled on one drug and will require two or more antihypertensive agents selected from different drug classes. Resistant hypertension is defined as the failure to achieve goal BP in patients who are adhering to full doses of an appropriate three-drug regimen that includes a diuretic.

The hypothesis of hypertension being related to diseases of kidney was entertained way back in 1827 by Richard Bright. However, this notion remained controversial until Goldblatt et al. discovered a clear relationship between renal ischemia and hypertension in 1934 proving an unequivocal role of the kidney in blood pressure regu1ation [6].

After initial work by Danielopolu, Bruning and Pende in 1923, several surgeons performed various degrees of sympathectomy with less aggressive to more complete techniques such as the removal of all thoracic and upper three lumbar ganglia together with the splanchnic nerves and the coeliac ganglion [7]. However, surgical techniques for management of resistant hypertension are obsolete now and only of historical importance.

It is well known that the kidney has major role in blood pressure regulation by pressure natriuresis and sodium balance as well as neurohormonal factors and its influence on the sympathetic nervous system activity. This complex interplay of various neurohormones in the pathogenesis of hypertension has been an intense area of research.

Vascular resistance, sodium balance, extracellular fluid volume and sympathetic activity is influenced by the renin-angiotensin-aldosterone system (RAAS). Efferent renal sympathetic nerves innervate the preglomemlar and postglomerular vasculature, all elements of the juxtaglornerular apparatus and virtually all segments of the nephron in both cortical and medullo-papillaiy regions. It releases nor epinephrine as the primary neurotransmitter.

The cell bodies of these afferent sympathetic fibres are located in the dorsal root ganglia and are connected to the autonomic centers in the central nervous system (mainly within the paraventral nucleus of the hypothalamus). They contain substance $P$, calcitonin gene-related peptide and adenosine as the primary neurotransmitter. 
The signals are transmitted to the spinal cord and central nervous system via afferent fibers. Both efferent and afferent fibers enter and exit the kidneys within the adventitia of the renal arterial wall. Sympathetic nervous system regulates the renin secretion by two mechanisms. First by intrarenal baroreceptors of the afferent arterioles sensitive to changes in renal arterial perfusion(mechanoreceptors) and second by alterations in the delivery of sodium chloride to the macula densa cells of the distal tubule (chemoreceptors). The importance of the sympathetic nervous system has increasingly been recognized in regulation of blood pressure.

Afferent sympathetic fibers from the kidney also directly influence the overall sympathetic tone [8]. Variety of cardiovascular diseases such as congestive heart failure, myocardial infarction and kidney diseases as well as in metabolic conditions including diabetes mellitus, obesity and the metabolic syndrome are attributed to sympathetic overactivity [9]. Renal afferent nerve activity is increased in presence of ischemia or hypoxemia.

Renal afferent nerves further influences the overall sympathetic adrenergic activity by modulating posterior hypothalamic activity. Chronically elevated renal afferent activity seen in chronic renal failure is a major contributor to the initiation and maintenance of a high renal and overall sympathetic efferent activity. This may lead to adverse consequences including hypertension, vascular remodeling, left vermicular hypertrophy, ventricular arrhythmias and sudden cardiac death [10].

In summary, the kidney is a sensory organ richly innervated with baroreceptors and chemoreceptors. These receptors transmit information via afferent sympathetic fibers to the areas in the central nervous system that have a pivotal role in blood pressure control. Stimulation of these renal receptors either by ischemic metabolites, or by uremic toxins, or by electrical impulses, evoke reflex increases in sympathetic nerve activity and blood pressure [11].

Based on the above described role of the sympathetic nervous system in the pathophysiology of hypertension, the proven results of surgical sympathectomy and nephrectomy in various previous animal models and humans, the high prevalence and our inability in the optimal treatment of resistant hypertension in routine clinical practice despite a wide array of
Antihypertensive medications and, importantly, with the advent of innumerable transcatheter tools to selectively denervate the kidney without affecting the remainder of the abdominal and pelvic nervous system, the concept of catheter based renal sympathectomy or renal denervation was evaluated in various clinical trials. Of all the trials, simplicity HTN trials are the major randomized trials.

To explore the feasibility, safety and efficacy of selective renal sympathectomy via a radiofrequency catheter positioned into the renal arteries percutaneously, in 2007, a non-randomized prospective trial (Simplicity HTN 1) $[12,13,14]$ was initiated in patients with resistant hypertension. The denervation of the renal sympathetic nerves was performed with a specifically designed catheter, Ardian Symplicity ${ }^{\circledR}$ Catheter. Forty-five patients were included and treated with renal denervation.

They concluded that Catheter-based renal denervation causes substantial and sustained bloodpressure reduction, without serious adverse events, in patients with resistant hypertension. Simplicity HTN 2 [15] followed the first trial and was a multicentre, prospective, randomised trial, in which patients who had a baseline systolic blood pressure of $160 \mathrm{~mm} \mathrm{Hg}$ or more ( $\geq 150 \mathrm{~mm} \mathrm{Hg}$ for patients with type 2 diabetes), despite taking three or more antihypertensive drugs, were randomly allocated in a one-to-one ratio to undergo renal denervation with previous treatment or to maintain previous treatment alone (control group) at 24 participating centers.

52 patients who underwent renal denervation and $51(94 \%)$ of 54 controls were assessed for the primary endpoint at 6 months. Office-based blood pressure measurements in the renal denervation group reduced by $32 / 12 \mathrm{~mm} \mathrm{Hg}$ (SD 23/11, baseline of $178 / 96 \mathrm{~mm} \mathrm{Hg}, \mathrm{p}<0.0001$ ), whereas they did not differ from baseline in the control group (change of $1 / 0 \mathrm{~mm} \mathrm{Hg}$ [21/10], baseline of 178/97 $\mathrm{mm} \mathrm{Hg}, p=0.77$ systolic and $p=0.83$ diastolic).

They concluded that catheter-based renal denervation can safely be used to substantially reduce blood pressure in treatment-resistant hypertensive patients. After proof of concept, safety and favorable effects shown in both the above trials, a prospective, single-blind, randomized, shamcontrolled trial was planned (Simplicity HTN 3) [16], [17]. Patients with severe resistant hypertension were randomly assigned in a 2:1 ratio to undergo renal denervation or a sham procedure. 
The primary efficacy end point was the change in office systolic blood pressure at 6 months; a secondary efficacy end point was the change in mean 24-hour ambulatory systolic blood pressure. The primary safety end point was a composite of death, end-stage renal disease, embolic events resulting in end-organ damage, renovascular complications, or hypertensive crisis at 1 month or new renal-artery stenosis of more than $70 \%$ at 6 months.

A total of 535 patients underwent randomization. The mean $( \pm S D)$ change in systolic blood pressure at 6 months was $-14.13 \pm 23.93 \mathrm{~mm} \mathrm{Hg}$ in the denervation group as compared with $-11.74 \pm 25.94$ $\mathrm{mm} \mathrm{Hg}$ in the sham-procedure group $(P<0.001$ for both comparisons of the change from baseline), for a difference of $-2.39 \mathrm{~mm} \mathrm{Hg}$ (95\% confidence interval [CI], -6.89 to $2.12 ; \mathrm{P}=0.26$ for superiority with a margin of $5 \mathrm{~mm} \mathrm{Hg}$ ). This trial did not show a significant reduction of systolic blood pressure in patients with resistant hypertension 6 months after renal-artery denervation as compared with a sham control.

The present findings of renal denervation using a catheter-based approach for the treatment of 15 patients with resistant hypertension and follow up of 16 patients of resistant hypertension on optimal medical therapy showed that renal denervation led to a large and persistent decrease in blood pressure. This was achieved in patients resistant to multiple existing antihypertensive drug types and the fall in blood pressure at 1, 3 and 6 months were more significant in renal denervation group than drug therapy group.

However, the blood pressure response was also significant in drug therapy group at 1,3 and 6 months when compared to baseline blood pressures. Moreover, reduction of blood pressure was evident as early as 1 month, was further reduced at 3 months, and persisted through subsequent assessment at 6 months. The present study design is similar to simplicity HTN 2 study except that current was a non-randomized study. In simplicity HTN 1 trial post procedure office BP recordings were reduced by $20 / 10,24 / 11,25 / 11$, $23 / 11,26 / 14$, and $32 / 14 \mathrm{~mm} \mathrm{Hg}$ at $1,3,6,12,18$, and 24 months, respectively. In simplicity HTN 2 trial office-based blood pressure measurements in the renal denervation group reduced by $32 / 12 \mathrm{~mm}$ $\mathrm{Hg}(p<0 \cdot 0001)$, whereas they did not differ from baseline in the control group ( $p=0.77$ systolic and $\mathrm{p}=0.83$ diastolic).
Between group differences in blood pressure at 6 months were $33 / 11 \mathrm{~mm} \mathrm{Hg}(p<0 \cdot 0001)$. Our results show that our findings are in line with previous randomized studies on renal denervation like simplicity HTN 1 and simplicity HTN 2. Simplicity HTN 1 did not have a control group and compared blood pressures after renal denervation with baseline blood pressures.

The blood pressure reduction response of renal denervation group in the present study is also similar to simplicity HTN 1 trial. To overcome the selection bias and Hawthorne effect, the current study was planned to include control population similar to simplicity HTN 2. The blood pressure response in our patients is larger than what was achieved in simplicity HTN 2. There could be 2 reasons for the above response. Firstly, control group in simplicity HTN 2 did not show any significant fall in BP over 6 months, whereas our control group also showed a significant fall in BP from baseline at 6 months. So, the response in our denervation group could have been additive. Simplicity HTN 2 investigators explained the lack of fall in BP in control group suggesting that the blood pressures could have been reduced to reach a plateau over the 2 weeks of enrollment period with optimization of drug doses.

However, the current study enrolled the controls right from their first or second visit in cardiology OPD which can explain the occurred response. Secondly some bias and Hawthorne effect cannot be excluded completely in the present study as it was a non-randomized study. Noradrenaline spillover from the kidneys was not measured in the present study due to financial constraints. The present study had a total of 4 CKD patients in renal denervation group and none of them had any worsening of their baseline renal function until 6 months of follow up after the procedure. These findings are also consistent with previous similar trials.

Simplicity HTN-3 and its aftermath: The findings of simplicity HTN 3 contradicted the earlier published data regarding renal denervation. Simplicity HTN-3 trial underscores the importance of conducting blinded trials with sham controls in the evaluation of new medical devices before their clinical adoption. However, a limitation of simplicity HTN 3 trial was that medication adherence could not be confirmed. The results of this trial are specific to the catheter tested and cannot necessarily be generalized to other denervation systems [18]. 
There has been one other sham-controlled study, Simplicity Flex which failed to show benefit of RDN in BP lowering over doing a renal angiogram [19]. The results of other rigorously executed randomized controlled trials using the same or similar catheter systems like RAPID, Reduce-HTN, EnligHTN and DENERHTN [20] showed significant benefit of renal denervation in the treatment of resistant hypertension, whereas, the results of Oslo RDN [21] and Prague-15 [22] were not so favorable.

A recent meta-analysis of 15 RCTs by Agasthi $P$ et al [23] showed no significant benefit of RDN on blood pressure control in patients with resistant hypertension. Subgroup analysis of sham control studies showed a modest benefit in $24 \mathrm{hr}$. systolic blood pressure at 6 months with RDN.

They concluded that, based on the current evidence, patients with resistant hypertension and no identifiable secondary cause, maximized on lifestyle interventions and medical therapy by a hypertension specialist may benefit from renal denervation with an experienced operator. When renal denervation efficacy was assessed, using measurements of the spillover of norepinephrine from the renal sympathetic nerves to plasma, the only test validated to this point, denervation in simplicity HTN 3 patients was found to be incomplete and nonuniform between patients [24].

A Post hoc analysis of simplicity HTN 3 study by Kandzari DE et al showed that several potential confounding factors may partially explain the unexpected blood pressure responses in both the sham control and RDN groups suggesting how important the design of subsequent research should be to evaluate the potential role of RDN in the treatment of resistant hypertension [25].

Even today the clinical dilemma is still continuing [26] and further evaluation in rigorously designed clinical trials are necessary to validate alternative methods of renal denervation or to confirm previously reported benefits of renal denervation.

Various Novel Renal Denervation Technologies are also emerging (Image 3) and are in the pipeline. As the technology advances more clinical benefit is anticipated with newer ablation systems. With better understanding of the renal neuroanatomy and neurophysiology, RDN may be more successful if attention is given to the more distal segments of the artery where it is easier to access the nerves [27].

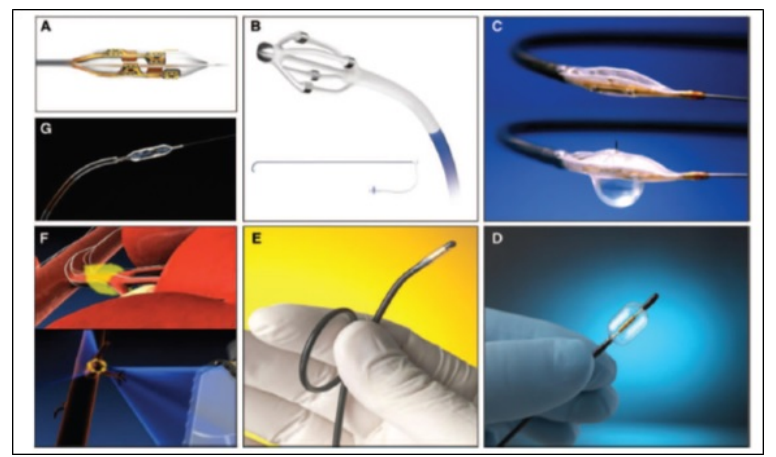

\section{Fig-3: Various emerging Novel Renal Denervation Technologies.}

A - Boston scientific V2 RDN system, B - St Jude Medical EnlightHTN Multi Electrode RDN system, C Mercator Medsystems Bullfrog Microinfusion catheter, D - Recor Paradise percutaneous RDN system, E Sound Interventions Sound 360 catheter, F - Kona Medical Surround Sound system (graphic representation), G - Coviden Maya One shot system

\section{Limitations}

The present study was a non-randomized case control study. Conventional RF ablation catheter has been used instead of simplicity Adrian system in our patients due to financial constraints. However, the current study achieved excellent safety and sustained blood pressure reduction response with our system similar to the response achieved in simplicity HTN trials 1 and 2 . This catheter may be a cheaper alternative to simplicity Adrian system particularly in developing countries like India. Vigorous screening for secondary causes of hypertension was not performed. Study population is small.

\section{Conclusion}

Overall, the study has shown that a simple catheterbased procedure to ablate renal sympathetic nerves could result in persistent reductions of blood pressure in patients with resistant hypertension. A significant BP reduction was observed when compared to patients on medical therapy. However, a significant effect on BP was not observed in a large randomized trial simplicity HTN-3 and major criticism was on the trials design, neuroscience failings and other limitations as discussed. The present study anticipate that future trials will address the effectiveness of renal denervation in resistant hypertension and also in disease states other than hypertension. 


\section{What do the current study add to the existing knowledge?}

This study shows that renal denervation is feasible, can be done at a low cost safely in patients with resistant hypertension and has a large bearing in low resource settings like India. However, it cannot be recommended yet, to all patients with resistant hypertension due to the lack of concrete evidence in the major trials.

\section{Author's contributions}

Dr. Raghuram Palaparti: Concept, study design, manuscript preparation

Dr. Imamuddin Syed: Guidance, manuscript preparation

\section{Acknowledgements}

Authors are immensely grateful to Dr. C Narasimhan for guiding us and conducting renal denervation procedure free of cost to the patients at CARE Hospital, Hyderabad. Authors would also like to thank Dr. Palaparthi Sairam for his contribution in statistical analysis of findings.

Abbreviations: SBP - Systolic blood pressure, DBP - Diastolic blood pressure, MBP - Mean blood pressure, HTN - Hypertension, CKD - Chronic Kidney Disease, RDN - Renal Denervation, GFR Glomerular Filtration Rate, MRI - Magnetic Resonance Imaging, MRA - Magnetic Resonance Angiography, CT - Computerized Tomography, OPD Out Patient Department, CVA - Cerebrovascular Accident

\section{Reference}

01. Calhoun DA, Jones D, Textor S, Goff DC, Murphy TP, Toto RD, et al. Resistant hypertensiondiagnosis, evaluation, and treatment- a scientific statement from the American Heart Association Professional Education Committee of the Council for High Blood Pressure Research. Circul. 2008;117(25)e510-e526.

Doi: $\quad$ 10.1161/CIRCULATIONAHA.108.189141 [Crossref]

02. Pisoni R, Ahmed MI, Calhoun DA. Characterization and treatment of resistant hypertension. Curr Cardiol Rep. 2009;11(6)407. doi: $10.1007 / \mathrm{s} 11886-009-0059-z \quad$ [Crossref]
03. Castrop H, Höcherl K, Kurtz A, Schweda F, Todorov V, Wagner C. Physiology of kidney renin. Physiol Rev. 2010;90(2)607-673.

doi: 10.1152/physrev.00011.2009 [Crossref]

04. James PA, Oparil S, Carter BL, Cushman WC, Dennison-Himmelfarb C, Handler J, Lackland DT, LeFevre ML, MacKenzie TD, Ogedegbe O, Smith SC. 2014 evidence-based guideline for the management of high blood pressure in adultsreport from the panel members appointed to the Eighth Joint National Committee (JNC 8). JAMA. 2014;311(5)507-520. doi: 10.1001/jama.2013.284427 [Crossref]

05. Textor SC. Revascularization in atherosclerotic renal artery disease. Kid Int. 1998;53(3)799811.

[Crossref]

06. Goldblatt H, Lynch J, Hanzal RF, Summerville WW. Studies on experimental hypertension- The production of persistent elevation of systolic blood pressure by means of renal ischemia. ] Exp Med. 1934;59(3)347-379.

doi: $10.1084 /$ jem.59.3.347 [Crossref]

07. Grimson KS. Total thoracic and partial to total lumbar sympathectomy and celiac ganglionectomy in the treatment of hypertension. Ann Surg. 1941;114(4)753-755. doi: 10.1097/00000658-194111440-00018 [Crossref]

08. Mark AL. The sympathetic nervous system in hyper-tension- a potential long-term regulator of arterial pressure. J Hypertens Off J Int Soc Hypertens. 1996;14(5)S159-S165.

[Crossref]

09. Malpas SC. Sympathetic nervous system overactivity and its role in the development of cardiovascular disease. Physiol Rev. 2010;90(2)513-557.

doi: 10.1152/physrev.00007.2009 [Crossref]

10. Schlaich MP, Sobotka PA, Krum H, Whitbourn R, Walton A, Esler MD. Renal denervation as a therapeutic approach for hypertension- novel implications for an old concept. Hypertens. 2009;54(6)1195-1201.

doi: $\quad$ 10.1161/HYPERTENSIONAHA.109.138610 [Crossref] 
11. Masuo K, Lambert GW, Esler MD, Rakugi H, Ogihara T, Schlaich MP. The role of sympathetic nervous activity in renal injury and end-stage renal disease. Hypertens Res. 2010;33(6)521528.

doi: $10.1038 / \mathrm{hr} .2010 .35$ [Crossref]

12. Krum $H$, Schlaich $M$, Whitbourn $R$, Sobotka PA, Sadowski J, Bartus K, et al. Catheter-based renal sympathetic denervation for resistant hypertension- a multicentre safety and proof-ofprinciple cohort study. The Lancet. 2009;373(9671)1275-1281.

doi: $10.1016 /$ S0140-6736(09)60566-3 [Crossref]

13. Krum H, Barman N, Schlaich M, Sobotka P, Esler $M$, Mahfoud F. Long-term follow-up of catheterbased renal sympathetic denervation for resistant hypertension confirms durable blood pressure reduction. J Am Coll Cardiol. 2012;59(13)E1704.

doi: $10.1016 / \mathrm{S} 0735-1097(12) 61705-7 \quad$ [Crossref]

14. Krum $H$, Schlaich MP, Sobotka PA, Böhm M, Mahfoud $F$, Rocha-Singh $K$, et al. Percutaneous renal denervation in patients with treatmentresistant hypertension- final 3-year report of the Symplicity HTN-1 study. The Lancet. 2014;383(9917)622-629.

doi: $10.1016 /$ S0140-6736(13)62192-3 [Crossref]

15. Symplicity HTN-2 Investigators. Renal sympathetic denervation in patients with treatment-resistant hypertension (The Symplicity HTN-2 Trial)- a randomised controlled trial. The Lancet. 2010;376(9756)1903-1909.

doi: $10.1016 /$ S0140-6736(10)62039-9 [Crossref]

16. Kandzari $D E$, Bhatt $D L$, Sobotka PA, O'Neill WW, Esler M, Flack JM, et al. Catheter-based renal denervation for resistant hypertension- rationale and design of the SYMPLICITY HTN-3 Trial. Clinical Cardiol. 2012;35(9)528-535.

doi: 10.1002/clc.22008 [Crossref]

17. Bhatt $D L$, Kandzari DE, O'Neill WW, D'Agostino R, Flack JM, Katzen BT, et al. A controlled trial of renal denervation for resistant hypertension. New Eng J Med. 2014;370(15)1393-1401. doi: 10.1056/NEJMoa1402670 [Crossref]
18. Persu A, Jin $Y$, Elmula FE, Renkin J, Høieggen $A$, Kjeldsen $S E$, et al. Renal denervation in treatment-resistant hypertension- a reappraisal. Curr Opi Pharmacol. 2015;21;48-52.

Doi: $10.1016 /$ j.coph. 2014. 12.013 [Crossref]

19. Desch S, Okon T, Heinemann D, Kulle K, Röhnert $K$, Sonnabend $M$, et al. Randomized sham-controlled trial of renal sympathetic denervation in mild resistant hyper-tension. Hypertens. 2015;65(6)1202-1208.

doi: 10.1161/HYPERTENSIONAHA.115.05283 [Crossref]

20. Azizi M, Sapoval M, Gosse P, Monge M, Bobrie G, Delsart $P$, et al. Optimum and stepped care standardised antihypertensive treatment with or without renal denervation for resistant hypertension (DENERHTN)- a multicentre, openlabel, randomised controlled trial. The Lancet. 2015;385(9981)1957-1965.

doi: $10.1016 /$ S0140-6736(14)61942-5 [Crossref]

21. Fadl Elmula $F E$, Hoffmann $P$, Larstorp $A C$, Fossum E, Brekke M, Kjeldsen SE, et al. Adjusted drug treatment is superior to renal sympathetic denervation in patients with true treatment-resistant hypertension. Hypertens. 2014;63(5)991-999.

doi: $\quad 10.1161 /$ HYPERTEN-SIONAHA.114.03246 [Crossref]

22. Rosa J, Widimský $P$, Toušek $P$, Petrák $O$, Čurila $K$, Waldauf $P$, et al. Randomized comparison of renal denervation versus intensified pharmacotherapy including spironolactone in true-resistant hypertension- six-month results from the Prague-15 study. Hypertens. $2015 ; 65(2) 407-413$.

doi: $\quad$ 10.1161/HYPER-TENSION-AHA.114.04019 [Crossref]

23. Agasthi P, Shipman J, Arsanjani R, Ashukem M, Girardo ME, Yerasi $C$, et al. Renal Denervation for Resistant Hypertension in the contemporary era- A Systematic Review and Meta-analysis. Sci Rep. 2019;9(1)6200.

doi: $\quad 10.1038 / \mathrm{s} 41598-019-42695-9 \quad$ [Crossref]

24. Illusions of truths in the Symplicity HTN-3 trialgeneric design strengths but neuroscience failings. J Am Soc Hypertens. 2014;8(8)593598. doi: 10.

1016/j.jash.2014.06.001 [Crossref] 
25. Kandzari DE, Bhatt DL, Brar S, Devireddy CM, Esler $M$, Fahy $M$, et al. Predictors of blood pressure response in the SYMPLICITY HTN-3 trial. Europe Heart J. 2014;36(4)219-227. doi: 10.1093/eurheartj/ehu441 [Crossref]

26. Ram CV. Status of Renal Denervation Therapy for Hypertension- Still in Search of the Magic Bullet. Circulation. 2019;139(5)601-603.

doi: 10.1161/circulationaha.118.037937 [Crossref]
27. Tzafriri AR, Mahfoud F, Keating JH, Markham PM, Spognardi A, Wong $G$, et al. Innervation patterns may limit response to endovascular renal denervation. J Am Coll Cardiol. 2014;64(11)1079-1087. doi: 10.1016/j.jacc.2014.07.937 [Crossref] 